\title{
MineCraft a Media for Resilience
}

\author{
Dorine Flies \\ EPIK (Encouraging programming in kids) \\ Mozilla foundation and ionCube Ltd \\ Canterbury, Kent, UK \\ Dorine.flies@gmail.com
}

\section{INTRODUCTION}

In 2010, Wyman et al. (2010) examined within a mental health framework 'Resilience', to promote a culture in young people in schools of building strategies, as a tool to self-manage the escalation of potential conflict points, aimed at mediating conduct in the classroom. This short paper aims to explore the scope for adapting the work by discovering why one might choose to employ digital media vs. traditional methods. This in an effort to extend the scope of the Wyman et al. (2010) methods to be inclusive of digital media, as an additional resource valued by youths to mediate adversity.

Adversity thus, we can agree builds resilience and without resilience the world of 'People' is that much harder a place to navigate, as adversity can often escalate into conflict points when left unmediated. Personalisation as a method, mediated by a media that we value, helps us to deal with adversity in ways meaningful to us, this as micro mechanisms that are there to help us bounce back as against. being overwhelmed by a given adverse situation.

The issue of adversity is further framed within a broader robust social framework context, that our children are no longer permitted to 'Fail', where every child is a winner on the schools sport pitches. This is in contradiction to the world of accountability and employability post school, where our youths are no longer protected from failing and yet have built little to no resilience at dealing with the effects of adversity (e.g., The Guardian 2015): "Exams have left my students incapable of thinking"; is thinking for yourself not a key component to making an informed choice and thus a tool that empowers the individual to build a resilience to adversity?

\section{SEEKING COMMON GROUND}

Minecraft is as much a media as any other 'Tool' that enables the making process to happen, be it a Paint brush, a Piano or a Person to an Algorithm, as prostheses whose functions are to output our imaginings as an extension of self, "Actor network theory" (Wikipedia 2015).

Making stuff with Minecraft, helps us connect with the physical world as well as developing the thinking for yourself skill as based on absorption as an additive process. Chodorow (1999) discusses the state of Absorption vs. Rejection of our social world illustrated by "This is not part of me, it is part of you" as what the other perceives value in, is rejected. This is a possible contributing factor to the self-sufficient man in a box syndrome Elias (2000) 'Homo Clausus', as a habit forming mindset that reenforces our young peoples' mindset that only 'their' social worlds values and understands them.

Absorption, thus as a tool, can be used to help us both align and seek common ground, not just with youths but as a bridge across the technology and generational divide through the process of making as our binding agent. Rather than focusing in on the media, which has scope to not only divide but create conflict, as we might just not be culturally competent enough to understand that media and thus reach a conclusion that 'This is not part of me, it is part of you', 'I'm not the gamer, you are', this as a self-imposed perception of self. This thus compounds the cultural chasm between two worlds, the pre digital yesterday and the digital today considering that about eight out of ten homes now own a next generation computer gaming console predominantly used by young people (The Telegraph 2015). 


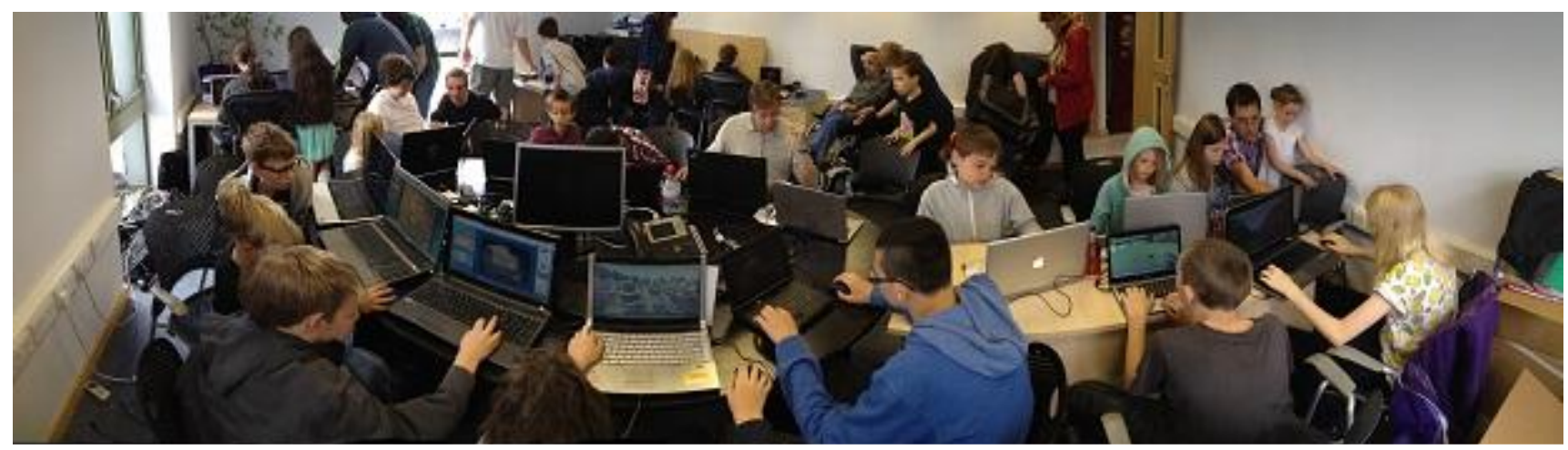

Figure 1: EPIK "Family open day": MineCraft computer coding with NetBeans IDE and JAVA modding diamond laying chickens: teach.mozilla.org teaching kit: Minecraft a flavor of Java by EPIK - Canterbury Kent

\section{THE BRAVE NEW OLD WORLD OF MAKERS}

This 'Process' based approach helps us to build resilience in dealing with new tasks based on a similar structure, by adapting what we have ourselves experienced; "There is an apprenticeship in swimming" argues Mauss (1973), who goes on to discuss the need to learn techniques before one can make it our own, as a process for the creative use of the 'Being natural' as part of three stages:

1. Repetition;

2. Interaction between doing and thinking;

3. The group as a reflection of the 'Tribe' one belongs to, that mediates conduct.

In any computer game challenge as differing degrees of adversity, is ever present, as is the social that mediates conduct. In Minecraft challenge might be set by the individual who wants to build something and struggles, so enlists help to achieve objectives, else it might manifest itself when your creation is blown up with TNT by another player. This where the 'intent' of the act might or might not be all about you. It could also be thoughtlessness or just doing it because the server admin didn't consider TNT a threat, so in fact it is nothing to do with you, your house, nor the countless hours spent making stuff.

Conversely the intent might also be entirely all about you and professional, thus as a tool to give an experience to the individual or group, of losing property within a youth justice context, thus adding meaning at a personalised level of loss through damage by the action of another; a life lesson in empathy?

You as the player learn how to deal with what the world throws at you within that sandbox environment, your window to the world outside your front door. Beck et al. (2004) suggests that young people who have grown up in a culture of gaming have a different take on personal failure, in their business and professional life, compared with their non-game-playing peers. They are more likely to perceive failure as a learning opportunity than as a measure of their own worth or ability.

\section{REFERENCES}

Beck, J. \& Wade, M. (2004) Got Game: How a New Generation of Gamers is Reshaping Business Forever. Boston, Massachusetts, Harvard Business School Press.

Chodorow, N. J. (1999) The Power of Feelings: Personal Meaning in Psychoanalysis, Gender, and Culture. New Haven, CT, Yale University Press

Elias, N. (2000) [1939] The Civilizing Process: Sociogenetic and Psycho genetic Investigations (trans. E. Jephcott, revised edition). Oxford, Blackwell.

The Guardian (February 2015) Secret Teacher: exams have left my students incapable of thinking. http://www.theguardian.com/teachernetwork/2015/feb/07/secret-teacher-examsstudents-thinking (retrieved 13 March 2015).

Mauss, M. (1973) Techniques of the body. Economy and Society, 2(1), 70-88.

The Telegraph (April 2015) Video games: eight out of ten homes own a next-gen games console. http://www.telegraph.co.uk/technology/videogames/4248136/Video-games-eight-out-of-tenhomes-own-a-next-gen-games-console.html (retrieved 20 April 2015).

Wikipedia (2015) Actor network. http://en.wikipedia.org/wiki/Actor-network theory (retrieved 13 March 2015).

Wyman, P. A., Cross, W., Hendricks Brown, C., Yu, Q., Tu, X., \& Eberly, S. (2010) Intervention to Strengthen Emotional Self-Regulation in Children with Emerging Mental Health Problems: Proximal Impact on School Behaviour. Journal of Abnormal Child Psychology, 38, 707-720. 